Revista Destaques Acadêmicos, Lajeado, v. 8, n. 4, 2016. ISSN 2176-3070 DOI: http://dx.doi.org/10.22410/issn.2176-3070.v8i4a2016.1222 www.univates.br/revistas

\title{
ANÁLISE DE AÇÚCARES TOTAIS, REDUTORES E NÃO- REDUTORES EM REFRIGERANTES PELO MÉTODO TITULOMÉTRICO DE EYNON-LANE
}

\author{
Gabriela Lima dos Santos ${ }^{1}$, Ruan Ezequiel Gemmer², Eniz Conceição Oliveira ${ }^{3}$
}

Resumo: Os refrigerantes são compostos principalmente de água potável, açúcares e/ ou edulcorantes, suco ou extrato de fruta e gás carbônico. O açúcar está presente na faixa de $8 \%$ a $12 \%$ do produto final, sendo um importante item a ser avaliado em análises laboratoriais pela indústria. O Método titulométrico de oxirredução de Eynon-Lane é o método oficial do MAPA para determinação quantitativa deste insumo no produto final. Buscou-se identificar a quantidade de açúcares e o tipo de açúcar utilizado em amostras de refrigerantes de diferentes empresas, para isso, aplicou-se o método oficial para a determinação de açúcares, onde quantificou-se os açúcares redutores, não redutores e totais (AT) na bebida que está na prateleira. Os resultados obtidos variam entre $8,76 \%$ a $10,69 \%$ de AT na amostra, verificando-se uma diferença mínima entre os açúcares totais informados nos rótulos das amostras dos encontrados nas análises.

Palavras-chave: Refrigerante. Açúcares totais. Açúcares redutores. Açúcares não redutores. Eynon-Lane. Fehling.

\section{INTRODUÇÃO}

O refrigerante é uma bebida não alcoólica, formulada essencialmente por água potável, suco ou extrato vegetal de sua origem, com o acréscimo de açúcares e/ou edulcorantes, sendo gaseificado através da adição de dióxido de carbono na própria indústria (BRASIL, 2009; BRASIL, 2015).

Segundo Fisberg, Amâncio e Lottenberg (2002), os primeiros relatos de bebidas baseadas em extrato de noz de cola, diluídas em água com açúcar, surgiram no final do século XIX e início do século XX. Após, observou-se uma rápida aceitação e difusão de diversas bebidas gaseificadas e adoçadas de

1 Acadêmica do curso de Engenharia Química da Univates. E-Mail: gabbylima96@hotmail.com

2 Acadêmico do curso de Engenharia Química da Univates. E-Mail: ruangemmer@hotmail.com

3 Doutora em Química pela UFRGS. Professora titular da Univates. E-Mail: eniz@univates.br 
diferentes sabores pelo mundo, as quais ficaram conhecidas como refrigerantes. Conforme Lima e Afonso (2008), a primeira indústria de refrigerantes surgiu nos Estados Unidos, no ano de 1871. No Brasil, os registros datam que em 1906 surgiram as primeiras indústrias deste tipo de bebida.

O refrigerante tem como um dos principais ingredientes o açúcar, o qual concede o gosto adocicado característico da bebida. No brasil, "As indústrias de refrigerantes são as maiores consumidoras de açúcar do mercado brasileiro" (MENDA, 2011, texto digital), sendo que o tipo de açúcar comumente adicionado é a sacarose $\left(\mathrm{C}_{12} \mathrm{H}_{22} \mathrm{O}_{11}\right)$, na proporção de $8 \%$ a $12 \%$ do produto final. Fisberg, Amâncio e Lottenberg (2002) informam que o tipo de açúcar pode variar de produto para produto, sendo também utilizados glicose, galactose, frutose, lactose e maltose.

Os refrigerantes de baixas calorias, conhecidos como diet ou zero, têm os açúcares substituídos por edulcorantes, que são substâncias adoçantes que conferem sabor adocicado ao produto e tem baixíssimo ou nenhum teor calórico (LIMA; AFONSO, 2008). Segundo a Instrução Normativa $N^{\circ}$ 30, de 27 de setembro de 1999 do Ministério da Agricultura, Pecuária e Abastecimento (MAPA), as bebidas dietéticas devem ter a mesma formulação das bebidas convencionais, com exceção do açúcar que deve ser substituído, inteiramente, por edulcorantes, sendo que o teor de açúcares na bebida não pode ultrapassar $0,5 \%$ do produto final.

A análise dos açúcares nos alimentos tem alta importância no controle de qualidade dos produtos finais. No refrigerante o açúcar além de ser responsável por adoçar o produto, também é responsável por encorpar o produto final (LIMA; AFONSO, 2008). Rosa, Cosenza e Leão (2006) afirmam que o Brasil é o terceiro maior mercado de refrigerantes do mundo, ficando atrás apenas de Estados Unidos e México, sendo o $28^{\circ}$ maior consumidor da bebida. Isso mostra a ampla difusão desta bebida no país e no mundo e a necessidade de um rígido controle de qualidade do produto.

Os açúcares são classificados como carboidratos, possuindo subclassificações de acordos com suas características químicas. Bruice (2014) esclarece que os carboidratos são classificados de duas formas: os carboidratos simples que são os monossacarídeos; os carboidratos complexos, que são compostos por dois ou mais monossacarídeos ligados entre si. Os complexos que possuem apenas dois monossacarídeos ligados entre si, são classificados como dissacarídeos. Entre três a dez monossacarídeos ligados entre si, classificam-se como oligossacarídeos e acima disto os carboidratos complexos são classificados como polissacarídeos.

Dentre os carboidratos classificados como monossacarídeos, encontram-se principalmente a glicose, a frutose e a galactose. A sacarose, a maltose e a lactose são exemplos de dissacarídeos e o amido é um exemplo de polissacarídeo (BRUICE, 2014). A sacarose, açúcar proveniente da cana de açúcar e comumente utilizado na fabricação de refrigerantes conforme Fisberg, 
Amâncio e Lottenberg (2002), é composta por uma molécula de glicose ligada a uma molécula de frutose, ambos monossacarídeos.

Os monossacarídeos são conhecidos também como açúcares redutores (AR), pois em sua estrutura química possuem um grupo de aldeído ou cetona que ficam livres em solução aquosa e são capazes de reduzir o bromo $\left(\mathrm{Br}_{2}\right)$. Logo, os demais açúcares, como os dissacarídeos e os oligossacarídeos, são conhecidos como não redutores (ANR), pois não possuem aldeídos ou cetonas livres em soluções aquosas, as quais são capazes de reduzir o bromo (BRUICE, 2014).

Nos carboidratos complexos (não redutores), deve ser realizada uma hidrólise prévia, conhecida também por inversão, para que seja possível realizar a titulação de oxirredução do método de Eynon-Lane. A hidrólise é a alteração de uma substância complexa, a qual é quebrada em moléculas menores, utilizando água juntamente com ácido ou enzima, como catalisadores (MCWILLIAMS, 2016). Bruice (2014) explica que nos carboidratos a hidrólise quebra moléculas complexas, na presença de água fortemente acidificada juntamente com calor, em moléculas simples de monossacarídeos. Esses monossacarídeos, caso estejam presentes na amostra, não se hidrolisam. $\mathrm{Na}$ hidrólise da sacarose, obtém-se glicose e frutose, dois monossacarídeos (redutores), conforme mecanismo de reação apresentado na Figura 1.

Figura 1 - Mecanismo de hidrólise da sacarose em meio ácido.

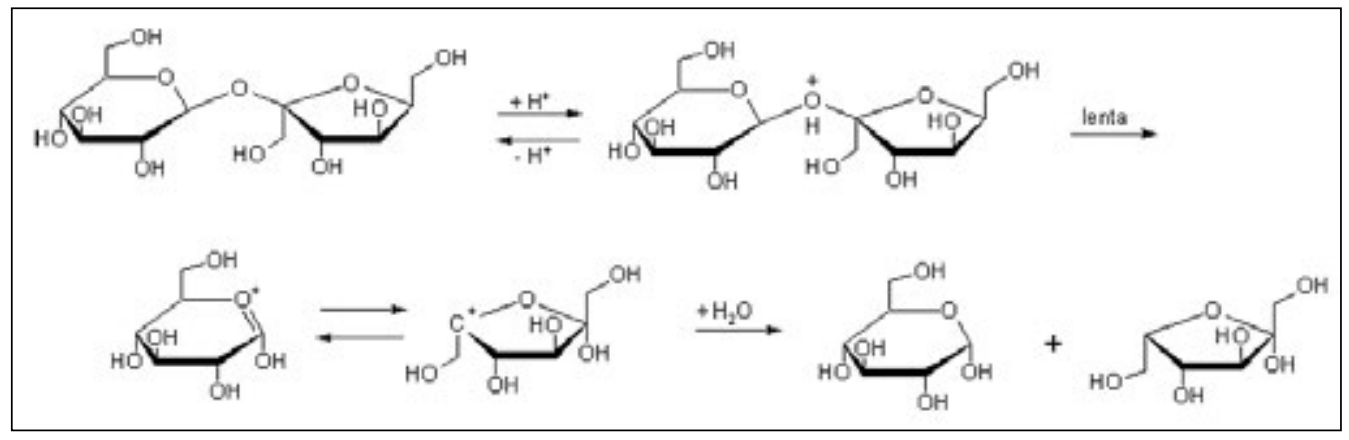

Fonte: Gabriel (2009, p. 19)

O objetivo deste trabalho foi quantificar os açúcares redutores, não redutores e totais, em amostras de refrigerantes, de diferentes marcas e sabores. Verificou-se com isso se os rótulos das amostras estavam de acordo com as quantidades de açúcares encontradas nas análises titulométricas.

\section{METODOLOGIA}

Para o estudo coletaram-se seis amostras de refrigerante, sendo dois de sabor cola, dois de sabor guaraná, um do tipo cola zero e um do tipo guaraná 
zero, de duas marcas distintas. Na coleta das amostras, as mesmas encontravamse em temperatura ambiente, com as embalagens seladas, e dentro de seus prazos de validade. Na quantidade de cada amostra coletada, levaram-se em consideração as análises em triplicatas. A Tabela 1 apresenta a nomenclatura utilizada para a identificação das amostras.

Tabela 1 - Nomenclatura das amostras de refrigerantes coletadas

\begin{tabular}{lcc}
\hline \multicolumn{1}{c}{ Tipo da amostra } & Empresa A & Empresa B \\
\hline Refrigerante de Cola & RC.A & RC.B \\
Refrigerante de Guaraná & RG.A & RG.B \\
Refrigerante Zero & RZC.A & RZG.B \\
\hline
\end{tabular}

Fonte: Dos autores.

Para a definição dos sabores de refrigerantes utilizados, considerouse os refrigerantes mais vendidos no Brasil. Conforme Rosa, Cosenza e Leão (2006), o sabor cola representa $50,9 \%$ das vendas e o refrigerante de sabor guaraná, o segundo mais vendido, caracteriza $24,5 \%$ das vendas do mercado de refrigerantes brasileiros.

A metodologia oficial no Brasil para a determinação de açúcares ou carboidratos, é o método titulométrico de oxirredução de Eynon-Lane, a qual é regulamentada para aplicação em bebidas, como os refrigerantes, pelo MAPA, através da Instrução Normativa $\mathrm{N}^{\circ} 24$ de 08 de setembro de 2005. Tal método é capaz de detectar somente os monossacarídeos presentes na amostra, e para os demais carboidratos deve-se realizar a hidrólise (inversão) dos mesmos (PEREIRA, 1933).

A metodologia utilizada para determinar a quantidade de açúcares redutores (AR), açúcares não redutores (ANR) e açúcares totais (AT), é descrita pelo Instituto Adolfo Lutz (2008) e pelo MAPA (2005).

Para a análise, utilizaram-se os seguintes equipamentos: balança analítica (marca Shimadzu, modelo AUX220), forno mufla digital (marca Hypper Química, capacidade de $16 \mathrm{~L}$, temperatura máxima de $1200^{\circ} \mathrm{C}$ ), chapaaquecedora e agitadora (marca Ikamag, modelo RH-KT/C), banho maria (marca Delta/Biomatic).

Utilizaram-se os seguintes reagente analíticos: Hidróxido de sódio PA $(\mathrm{NaOH})$, tartarato duplo de sódio e potássio $\mathrm{PA}\left(\mathrm{KNaC}_{4} \mathrm{H}_{4} \mathrm{O}_{6}\right)$, sulfato de cobre II penta hidratado $\left(\mathrm{CuSO}_{4} \cdot 5 \mathrm{H}_{2} \mathrm{O}\right)$, acetato de chumbo $\mathrm{PA}\left(\mathrm{Pb}\left(\mathrm{C}_{2} \mathrm{H}_{3} \mathrm{O}_{2}\right)_{2}\right)$, sulfato de sódio anidro $\left(\mathrm{Na}_{2} \mathrm{SO}_{4}\right)$, glicose $\mathrm{PA}\left(\mathrm{C}_{6} \mathrm{H}_{12} \mathrm{O}_{6}\right)$, ácido clorídrico $\mathrm{PA}(\mathrm{HCl})$, azul de metileno PA $\left(\mathrm{C}_{16} \mathrm{H}_{18} \mathrm{ClN}{ }_{3} \mathrm{~S}\right)$, álcool etílico PA $\left(\mathrm{C}_{2} \mathrm{H}_{6} \mathrm{O}\right)$.

Inicialmente preparou-se as soluções de: hidróxido de sódio $40 \%(\mathrm{~m} / \mathrm{v})$, solução saturada de acetato de chumbo $20 \%(\mathrm{~m} / \mathrm{v})$, solução de azul de metileno 
1\% (m/v). Após preparou-se a solução de Fehling A, diluindo-se 17,3195 g de sulfato de cobre II penta hidratado em um balão volumétrico de $500 \mathrm{~mL}$ com água deionizada. A solução de Fehling $\mathrm{B}$, diluiu-se $86,50 \mathrm{~g}$ de tartarato de sódio e potássio PA, juntamente com 62,50 g de hidróxido de sódio PA em um balão volumétrico de $500 \mathrm{~mL}$ com água deionizada. Padronizou-se as soluções de Fehling A e B, em triplicata, adicionando $10 \mathrm{~mL}$ de cada solução em um erlenmeyer de $250 \mathrm{~mL}$ com $40 \mathrm{~mL}$ de água deionizada. Levou-se à fervura a solução e titulou-se, gota a gota, com solução de glicose $1 \%(\mathrm{~m} / \mathrm{v})$ recentemente preparada, com auxílio de azul de metileno (1\%) como indicador, para calcular o fator das soluções de Fehling conforme apresentado na Equação 1.

$$
f=\frac{M \times V}{100}
$$

Equação 1

Onde: $\mathrm{M}=$ massa de glicose anidra (g)

$\mathrm{V}=$ Volume gasto na titulação $(\mathrm{mL})$

As amostras foram abertas somente na hora do preparo das mesmas para a análise, onde foram colocadas em um béquer para a desgaseificação com auxílio de uma barra magnética e um agitador.

Para a análise de açúcares redutores, pipetou-se $5 \mathrm{~mL}$ da amostra desgaseificada para um balão volumétrico de $100 \mathrm{~mL}$. Para as amostras sabor cola descoloriu-se com solução saturada de acetato de chumbo $20 \%$ e sulfato de sódio PA, e posterior filtração em balão volumétrico de $100 \mathrm{~mL}$. Após completar o volume, a amostra foi titulada.

Para os açúcares não redutores, pipetou-se $50 \mathrm{~mL}$ da solução final para análise de açúcares redutores para um balão volumétrico de $100 \mathrm{~mL}$. Acidificou-se com 1,5 mL de ácido clorídrico P.A. e levou-se a solução para o banho maria a $100 \pm 2{ }^{\circ} \mathrm{C}$ por trinta minutos. Após resfriada, a solução foi neutralizada com solução de hidróxido de sódio $40 \%$. Avolumou-se o balão e titulou-se a amostra.

Para receber a solução titulante, preparou-se uma solução com $10 \mathrm{~mL}$ de cada solução de Fehling com $40 \mathrm{~mL}$ de água deionizada. Após iniciar fervura, adicionou-se, gota a gota, a amostra contida na bureta para o erlenmeyer, com fervura constante desta solução. Ao início da titulação, observou-se uma cor azul intensa que ao mudar de coloração foi acrescentado uma gota de azul de metileno $(1 \%)$ e continuou-se a titulação até o desaparecimento da coloração azul e o surgimento da cor avermelhada indicando viragem (INSTITUTO ADOLFO LUTZ, 2008; MAPA, 2005).

Ao adicionar o titulante na solução de Fehling, os monossacarídeos reduzem o íon $\mathrm{Cu}^{2+}$, de coloração azulada em meio tartárico alcalino, para óxido de cobre $\mathrm{I}\left(\mathrm{Cu}_{2} \mathrm{O}\right)$, com coloração avermelhada, o qual precipita no meio. A fervura da solução de Fehling é necessária para acelerar a reação e também para não ocorrer a oxidação indesejada do $\mathrm{Cu}^{1+}\left(\mathrm{Cu}_{2} \mathrm{O}\right)$ para $\mathrm{Cu}^{2+}$. Tal titulação deve ser realizada em menos de 3 minutos, devido a decomposição dos açúcares 
expostos à ação prolongada de calor (PEREIRA, 1933; INSTITUTO ADOLFO LUTZ, 2008; TAVARES ET AL., 2010).

Figura 2 - Mecanismo da reação entre o monossacarídeo presente na amostra e o íon $\mathrm{Cu}^{2+}$, precipitando o $\mathrm{Cu}_{2} \mathrm{O}$

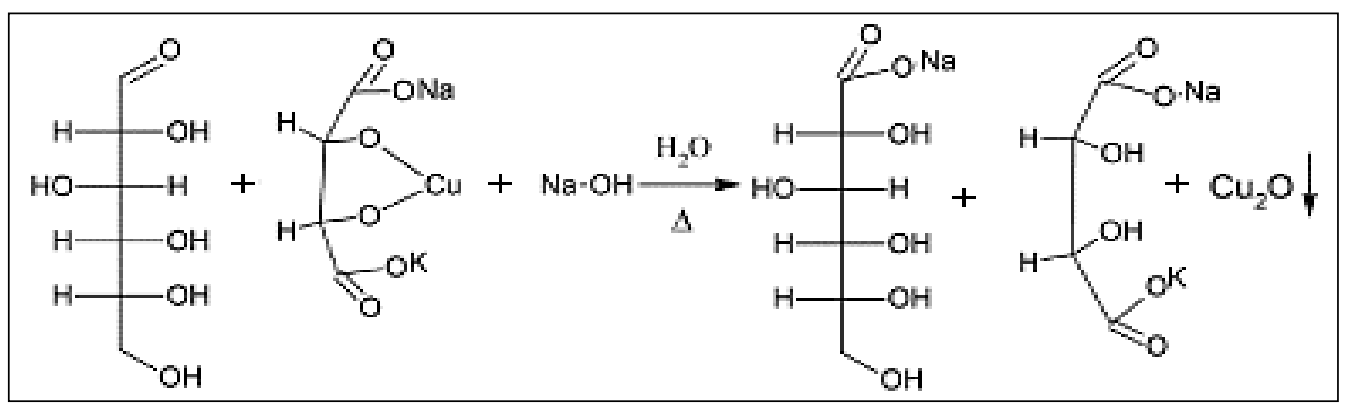

Fonte: Adaptado de Tavares et al. (2010).

Os açúcares redutores e não redutores são expressos em glicose e sacarose, respectivamente, pelos seguintes cálculos a partir das equações 2 e 3 .

$$
\begin{array}{lc}
\% \text { AR em glicose }=\frac{100 \times v b \times f}{M \times V} & \text { Equação } 2 \\
\% \text { ANR em sacarose }=\frac{100 \times v b \times 2 \times f}{M \times V} \times 0,96 & \text { Equação 3 }
\end{array}
$$

Os Açúcares totais são expressos pelo cálculo a seguir, conforme Equação 4.

$\% A T=$ AR em glicose + ANR em sacarose Equação 4

Onde: $\mathrm{vb}=$ volume do balão volumétrico utilizado $(\mathrm{mL})$.

$\mathrm{f}=$ fator da solução de Fehling.

$\mathrm{M}=$ Quantidade de amostra inicial utilizada para a análise.

$\mathrm{V}=$ Volume gasto na titulação $(\mathrm{mL})$.

\section{RESULTADOS E DISCUSSÃO}

Na Tabela 2, observa-se os resultados de açúcares redutores, açúcares não redutores e açúcares totais obtidos no ensaio de cada amostra com o desvio padrão calculado. 
Tabela 2 - Resultados obtidos na análise de açúcares em amostras de refrigerantes

\begin{tabular}{lccc}
\hline Amostra & $\begin{array}{c}\text { Açúcares Redutores } \\
(\mathbf{\%})\end{array}$ & $\begin{array}{c}\text { Açúcares Não } \\
\text { Redutores (\%) }\end{array}$ & Açúcares Totais (\%) \\
\hline RC.A & $4,74 \pm 0,02$ & $5,95 \pm 0,03$ & $10,69 \pm 0,05$ \\
RC.B & $8,09 \pm 0,16$ & $2,55 \pm 0,30$ & $10,64 \pm 0,47$ \\
RG.A & $0,33 \pm 0,00$ & $8,44 \pm 0,07$ & $8,77 \pm 0,07$ \\
RG.B & $1,31 \pm 0,01$ & $7,46 \pm 0,10$ & $8,77 \pm 0,10$ \\
RZC.A & Não quantificável & Não quantificável & Não quantificável \\
RZG.B & Não quantificável & Não quantificável & Não quantificável \\
\hline
\end{tabular}

Fonte: Dos autores.

Verifica-se na Tabela 2 que os valores obtidos para os açúcares redutores e não redutores são diferentes. Tal diferença encontrada pode estar relacionada à tipos diferentes de açúcares empregados na fabricação de cada refrigerante, que pode mudar de acordo com o fabricante e de acordo com o tipo de produto conforme citado por Fisberg, Amâncio e Lottenberg (2002). Observa-se que os refrigerantes de sabor guaraná (RG.A e RG.B) possuem menos açúcares em suas formulações que os refrigerantes de sabor cola (RC.A e RC.B), chegando a uma diferença percentual de aproximadamente $18 \%$.

Observa-se através do método de análise empregado que não é possível quantificar os açúcares presentes nos refrigerantes zero, visto que nas titulações das amostras não houve a viragem do reagente de Fehling, mesmo utilizando alíquotas superiores nestas amostras de refrigerantes, evidenciando que as quantidades de açúcares presentes na formulação dessas amostras são mínimas ou inexistentes.

Na Tabela 3 é possível verificar a quantidade de açúcares totais encontradas através das análises realizadas nas amostras e o teor de açúcar que cada fabricante declara ter dentro do produto conforme o rótulo de cada amostra. 
Tabela 3 - Quantidade de açúcares totais encontrados através da análise $X$ quantidade de açúcares totais informado nos rótulos

\begin{tabular}{|c|c|c|}
\hline Amostra & Açúcares Totais (\%) & $\begin{array}{c}\text { Açúcares Totais } \\
\text { informado no rótulo (\%) }\end{array}$ \\
\hline RC.A & $10,69 \pm 0,05$ & 10,50 \\
\hline RC.B & $10,64 \pm 0,47$ & 11,00 \\
\hline RG.A & $8,77 \pm 0,07$ & 9,00 \\
\hline RG.B & $8,77 \pm 0,10$ & 9,00 \\
\hline RZC.A & Não quantificável & 0,00 \\
\hline RZG.B & Não quantificável & 0,00 \\
\hline
\end{tabular}

Fonte: Dos autores.

Conforme a Tabela 3, é possível verificar que os valores encontrados para os açúcares totais nas amostras estão muito próximos dos valores informados pelos fabricantes de cada amostra nos rótulos das embalagens, obtendo-se uma diferença percentual mínima entre as amostras ao levar-se em consideração o desvio padrão obtido. Demiate et al. (2002) encontrou valores de açúcares totais entre $11,11 \%$ a $11,71 \%$ para a análise de refrigerantes de cola de três marcas distintas pelo método de Eynon-Lane, assim como, para refrigerante de guaraná, encontrou um valor de $11,10 \%$ de açúcares totais. Tais diferenças entre os valores encontrados por Demiate et al. (2002) e este estudo, devem-se ao fato de serem analisados diferentes lotes de produtos, diferentes marcas e amostras de refrigerantes e um longo período de tempo entre um estudo e outro, o que pode ocasionar em mudanças de formulações, variações entre lotes e variações entre metodologias utilizadas. A Figura 2 apresenta um resumo dos resultados obtidos para as amostras em estudo e dados constantes em seus rótulos. 
Figura 2 - Valores de açúcares encontrados e valor de açúcar total rotulado

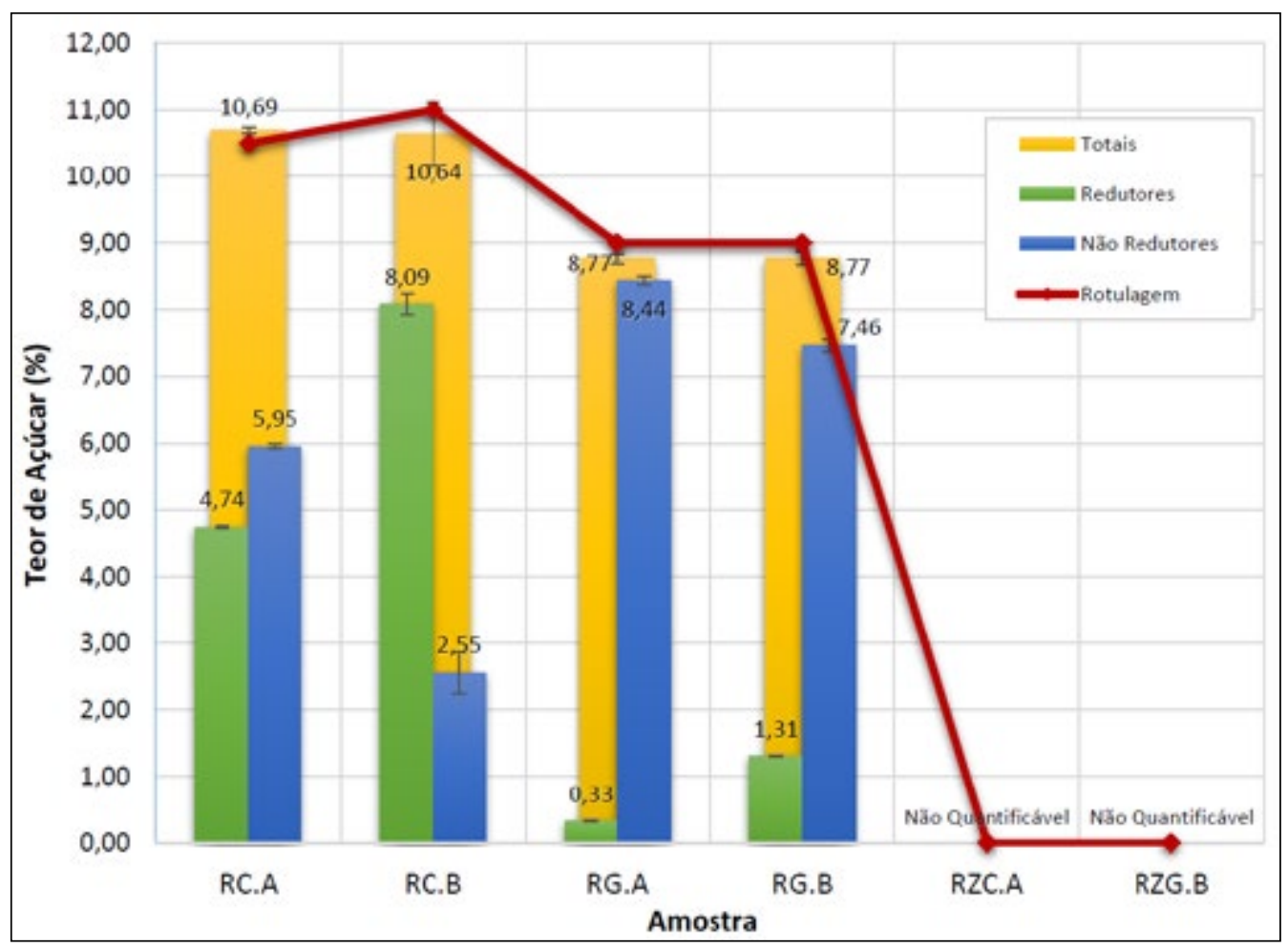

Fonte: Dos autores.

A partir da Figura 2 é possível verificar a quantidade de açúcares redutores (coluna verde), açúcares não redutores (coluna azul), açúcares totais (coluna amarela) e o teor de açucares totais informados na rotulagem de cada amostra (linha em vermelho), juntamente com o desvio padrão das análises que se realizaram.

Verifica-se que nos dois refrigerantes de sabor guaraná, RG.A e RG.B, observa-se a predominância da utilização de açúcares não redutores (como a sacarose), sendo este, utilizado na proporção de $96 \%$ e $85 \%$ respectivamente, do total de açúcares adicionados no produto. Em refrigerantes de cola, tem-se uma variação entre as duas marcas, sendo que na amostra RC.A, do total dos açúcares adicionados, cerca de $56 \%$ foi açúcar não redutor. Em contrapartida, na amostra RC.B, este tipo de açúcar representa apenas $24 \%$ de todos os açúcares adicionados, sendo utilizado predominantemente açúcares redutores.

Vicente, Neves e Meleiro (2014) afirmam que o erro na análise de Eynon-Lane é influenciável principalmente pela bureta utilizada no processo de titulação e também pela experiência do analista na análise em questão. Ainda assim, Vicente, Neves e Meleiro (2014) e Demiate et al. (2002) concluíram que a variação encontrada no método é menor que $2 \%$, afirmando que esta 
metodologia de análise é segura e confiável. Dornemann (2016) e Vicente, Neves e Meleiro (2014) compararam o método de análise de açúcares de Eynon-Lane com outros métodos possíveis de serem utilizados, como o de refratômetro, o de espectrofotômetro de Somogyi-Nelson e o de cromatografia líquida de alta eficiência, onde todos os métodos apresentaram resultados próximos nas amostras que cada autor utilizou, constatando-se a eficiência e a confiabilidade no método titulométrico de oxirredução de Eynon-Lane.

\section{CONSIDERAÇÕES FINAIS}

Verificou-se com o estudo, que as diferentes marcas de refrigerantes possuem distintas quantidades de açúcares redutores e não redutores em suas formulações, observando-se que os açúcares totais encontrados nas amostras, estão próximos dos valores informados nos rótulos de cada uma, sendo que, não há legislação especifica para a quantidade total de açúcares dentro dos refrigerantes não dietéticos. Nos refrigerantes do tipo zero pode-se afirmar que, caso possuam açúcares nas amostras, os mesmos não irão superar o limite definido pela legislação brasileira.

\section{REFERÊNCIAS}

BRASIL. Decreto $\mathrm{N}^{\circ}$ 6.871, de 04 de junho de 2009. Lei $\mathbf{N}^{\mathrm{o}}$ 8.918, de 14 de julho de 1994. Disponível em: <https://www.planalto.gov.br/ccivil_03/_ato2007-2010/2009/ decreto/d6871.htm>. Acesso em: 19 nov. 2016.

BRASIL. Decreto $\mathrm{N}^{\circ}$ 8.592, de 16 de dezembro de 2015. Lei $\mathbf{N}^{\circ}$ 8.918, de 14 de julho de 1994. Disponível em: < https://www.planalto.gov.br/ccivil_03/_Ato2015-2018/2015/ Decreto/D8592.htm\#art2>. Acesso em: 19 nov. 2016.

BRUICE, Paula Y. Fundamentos de química orgânica. 2. Ed. São Paulo: Pearson Education do Brasil, 2014. E-book. Disponível em: <http:/ / univates.bv3.digitalpages. com.br/users/publications/9788543006543/pages/-16>. Acesso em: 05 nov. 2016.

DEMIATE, Ivo M. et al. Determinação de açúcares redutores e totais em alimentos: comparação entre método colorimétrico e titulométrico. Revista Publicatio UEPG. Paraná, v. 8, n. 1, p. 65-78, 2002. Disponível em: <http:/ /www.revistas2.uepg.br/ index.php/exatas/article/view/772/677>. Acesso em: 06 nov. 2016.

DORNEMANN, Guilherme M. Comparação de métodos para determinação de açúcares redutores e não-redutores. Departamento de Engenharia Química UFRGS. Jul. 2010. Disponível em: < https:/ / www.lume.ufrgs.br/bitstream/ handle/10183/143940/000998082.pdf?sequence=1>. Acesso em: 04 dez. 2016.

FISBERG, Mauro; AMÂNCIO, Olga M. S.; LOTTENBERG, Ana M. P. O uso de refrigerantes e a saúde humana. Revista Pediatria Moderna. São Paulo, v. 38, n. 6, p. 261-271, jun. 2002. Disponível em: <http:/ /www.moreirajr.com.br/revistas. asp?fase $=$ r003\&id_materia $=1959>$. Acesso em: 18 nov. 2016. 
GABRIEL, Juliana R. Estudo da hidrólise de carboidratos em meio neutro, utilizando mistura de ésteres derivados do óleo de mamona. Universidade de São Paulo. São Paulo, 2009. Tese de doutorado. Disponível em: <https: / /www.google.com.br/ url sa $=\mathrm{t} \& \mathrm{rct}=\mathrm{j} \& \mathrm{q}=\&$ esrc $=\mathrm{s} \&$ source $=$ web $\& \mathrm{~cd}=1 \& \mathrm{cad}=\mathrm{rja} \& u a c t=8 \& v e d=0$ ahUKEwir 7vXTvvLQAhUH15AKHcumD7EQFggbMAA\&url=http $\% 3 \mathrm{~A} \% 2 \mathrm{~F} \% 2 \mathrm{Fwww}$.teses.usp. br $\% 2$ Fteses $\% 2 F d i s p o n i v e i s \% 2 F 75 \% 2 F 75132 \% 2 F t d e-05012010-081105 \% 2 F p u b l i c o \% 2 F-$ JulianaRibeiroGabrielR.PDF\&usg=AFQjCNF_2fo10dc-6XP1fFNDdmpEjZEIAg > . Acesso em: 10 dez. 2016.

INSTITUTO ADOLFO LUTZ. Métodos físico-químicos para análise de alimentos. 4. Ed. São Paulo: Instituto Adolfo Lutz, 2008. E-book. Disponível em: <http:/ /www.ial. sp.gov.br/resources/editorinplace/ial/2016_3_19/analisedealimentosial_2008.pdf>. Acesso em: 16 out. 2016.

LIMA, Ana C. da S.; AFONSO, Júlio C. A química do refrigerante. Revista Química Nova na Escola. São Paulo, v. 31, n. 3, p. 210-215, ago. 2008. Disponível em: <http:/ / qnesc.sbq.org.br/online/qnesc31_3/10-PEQ-0608.pdf>. Acesso em: 18 nov. 2016.

MCWILLIAMS, Margaret. Alimentos: um guia completo para profissionais. 10. Ed. São Paulo: Manole, 2016. E-book. Disponível em: < http:/ / univates.bv3.digitalpages. com.br/users/publications/9788520436974/pages/-6>. Acesso em: 06 nov. 2016.

MENDA, Mari. Refrigerantes. Conselho Regional de Química - IV Região. São Paulo, 2011. Disponível em: <http:/ / www.crq4.org.br/refrigerantes>. Acesso em: 19 nov. 2016.

MINISTÉRIO DA AGRICULTURA, PECUARIA E ABASTECIMENTO - MAPA. Manual de Métodos de Análises de Bebidas e Vinagres - Açucares redutores (Método 14). Instrução Normativa $\mathbf{N}^{\circ}$ 24, de 08 de setembro de 2005. Disponível em: <http:/ / www.agricultura.gov.br/arq_editor/file/Aniamal/Laborat\%C3\%B3rios / Metodos\%20IQA/BEV/Nao\%20Alc/NAO\%20ALCOOLICOS\%20-\%2014\%20 ACUCARES\%20REDUTORES\%20NAO\%20REDUTORES\%20E\%20TOTAIS.pdf>. Acesso em: 16 out. 2016.

MINISTÉRIO DA AGRICULTURA, PECUARIA E ABASTECIMENTO - MAPA. Instrução Normativa $N^{\circ}$ 30, de 27 de setembro de 1999. Disponível em: <www. teornobre.com.br/IN_30.doc>. Acesso em: 16 nov. 2016.

PEREIRA, Cardoso A. Sobre a história da descoberta do licor de Fehling. Sociedade Portuguesa de Química e Física. Lisboa, 22 mai. 1933. Disponível em: <http:/ /www. spq.pt/magazines/RCPA/478/article/10001197/pdf>. Acesso em: 06 nov. 2016.

ROSA, Sergio E. S. da; COSENZA, José P.; LEÃO, Luciana T. de S. Panorama do setor de bebidas no Brasil. BNDES Setorial. Rio de Janeiro, n. 23, p. 101-150, mar. 2006. Disponível em: <http:/ /www.bndes.gov.br/SiteBNDES/export/sites/default/ bndes_pt/Galerias/Arquivos/conhecimento/bnset/set2304.pdf>. Acesso em: 05 nov. 2016. 
TAVARES, José T. de Q. et al. Interferência do ácido ascórbico na determinação de açúcares redutores pelo método de Lane e Eynon. Revista Química Nova. São Paulo, v. 33, n. 4, 2010. Disponível em: <http:/ /www.scielo.br/scielo.php?script=sci_ arttext\&pid=S0100-40422010000400008\&lng=en\&nrm=iso $>$. Acesso em: 04 dez. 2016.

VICENTE, Juarez; NEVES, Marcelo A.; MELEIRO, Luiz A. da C. Estimativa de incerteza expandida associada à análise de açúcares redutores pelo método de Lane-Eynon. Centro de Pesquisa e Processamento de Alimentos. Curitiba, v. 32, n. 1, p. 69-82, 2014. Disponível em: <http:/ / revistas.ufpr.br/alimentos/article/ view/37027/22822>. Acesso em: 16 nov. 2016. 